Research Article

\title{
Experimental and Numerical Investigation on Carbon Fiber-Reinforced Polymer-Strengthened Concrete Beam after High-Temperature Action of Asphalt Paving Construction
}

\author{
Xin Yuan $\mathbb{D}^{1},{ }^{1}$ Chaoyu Zhu ${ }^{D},{ }^{1}$ Wei Zheng, ${ }^{2}$ and Baijian Tang $\mathbb{D}^{1}$ \\ ${ }^{1}$ School of Civil Engineering, Suzhou University of Science and Technology, Suzhou 215011, China \\ ${ }^{2}$ Suzhou Zhongheng Access Bridge Co., Ltd., Suzhou 215000, China \\ Correspondence should be addressed to Xin Yuan; yuanxin9988@163.com
}

Received 2 August 2019; Accepted 25 November 2019; Published 19 December 2019

Academic Editor: Sanjay Nimbalkar

Copyright (c) 2019 Xin Yuan et al. This is an open access article distributed under the Creative Commons Attribution License, which permits unrestricted use, distribution, and reproduction in any medium, provided the original work is properly cited.

Numerical investigation of mechanical behavior of carbon fiber-reinforced polymer- (CFRP-) reinforced concrete beam after high-temperature action of asphalt paving construction was carried out in this study. The debonding failure of the CFRP plateconcrete interface was simulated by introducing the double debonding criterion. In order to compare with simulation results, specimens with different pavement schemes were tested to obtain experimental data. The load-deflection relationship, CFRP strain distribution, and crack propagation of specimens were compared with the numerical simulation results. The numerical simulation results showed good agreement with the experimental results. Additionally, the interface bonding stress distribution model and the calculation formula of the debonding bearing capacity were proposed. The proposed calculation model was proved to have good accuracy in predicting the strain of intermediate cracking debonding and the debonding bearing capacity of the CFRP-reinforced concrete beam after high-temperature action.

\section{Introduction}

In recent years, carbon fiber-reinforced polymer (CFRP) has widely been used for structural reinforcement. Due to its special material properties, it has shown good ability in improving structural load-carrying capacity. Many researchers studied the performance of the CFRP-strengthened structures [1-5]. Structural performance of the fiberreinforced polymer- (FRP-) concrete composite bridge deck was studied experimentally and numerically by Tian et al. [1]. CFRP-strengthened metallic shell was studied by Draidi et al. [2], and the buckling behavior was evaluated. The steelFRP composite bar- (SFCB-) reinforced concrete beam was investigated by Sun et al. [3], the moment-curvature behaviors were studied, and a design reference for the SFCB structure was provided. Kromoser et al. [5] evaluated CFRPultrahigh-performance concrete (UHPC) beam and provided a conceptual design method for building components.
At present, some studies have also considered the impact of special environments on the performance of CFRP plateconcrete interface [6-9]. Shi et al. [6] studied the interface bonding behavior of FRP-concrete by considering the coupling effect of freeze-thaw cycling and sustained load. Li et al. [7] conducted numerical simulation and experiment on the fatigue crack propagation behavior of CFRP-reinforced concrete beam under the heat-humidity environment. The interface bonding behavior of CFRP and concrete under freeze-thaw and acid-alkali cycling was investigated by Wang and Petrů [8], and mode I fracture evaluation was also conducted on the long-term performance of CFRPstrengthened concrete structure. In particular, Gallego et al. [9] conducted an experimental investigation on the shortterm strengthening of the CFRP-reinforced concrete beam after asphalt paving construction and concluded that the failure mode of specimens is usually manifested as debonding failure of the CFRP plate. 
In the previous research on CFRP reinforcement theory, many researches have been conducted on the numerical simulation analysis of the debonding of CFRP plate-reinforced concrete structures [10-16]. Tao and Chen [10] simulated the bonding behavior of single-shear specimens, and a simplified finite element model was proposed to simulate the bonding behavior of the interfacial debonding process. Daud et al. [11] studied the postfatigue behavior of CFRP-concrete interface in ABAQUS, and a cohesive surface model was adopted in the single-shear test model. Kadhim et al. [12] studied the interface of the damaged concrete beam with FEA. Mesoscale finite element and meshless finite element have been applied to the analysis of the CFRP-concrete interface debonding issue. Lu et al. [13] simulated the tensile and shear performance of FRP-reinforced concrete beam by considering the influence of element size. Teng et al. [14] and Coelho et al. [15] introduced the mesoscale element to study the bonding performance and cracking behavior of the near-surface-mounted (NSM) FRP-reinforced concrete structure. Abbasloo and Maheri [16] studied the FRP-honeycomb sandwich panels by using the finite element meshless method.

Although the application of the mesoscale finite element is beneficial to improve the accuracy of the finite element simulation calculation, the computational complexity of this method is relatively large, and it is not convenient for largescale application in civil engineering and scientific research. In addition, the meshless method has higher requirements for nonlinear problem analysis and is not suitable for widespread use in practical engineering as well. Through the above analysis, it is known that there is not much research on the impact of high-temperature environmental conditions of asphalt paving construction on the FRP-concrete interface. Although Gallego et al. [9] studied several aspects of CFRP plate-reinforced concrete structure after high-temperature effect of asphalt paving construction, and the interface behavior of CFRP-concrete structure needs to be further investigated.

Based on the CFRP plate reinforcement of the box girder bridge roof (Figure 1), this study investigated the effect of the high-temperature action of the asphalt paving construction on the interface of the CFRP plate and concrete. The object of numerical simulation analysis in this study is based on CFRP plate-concrete interface after high-temperature action, which is different from the previous research. The CFRP-concrete interface performance under stable conditions after high-temperature action is considered in this article. The instantaneous high-temperature effect of asphalt paving construction is not considered. Therefore, the numerical simulation analysis model in this article is based on the condition after high-temperature action.

The investigation in this paper can be divided into three parts: firstly, the temperatures of different deck paving schemes were tested to compare their thermal insulation performance. The flexural behavior of CFRP-reinforced concrete specimens after high-temperature action of asphalt paving construction was tested by four-point loading. Secondly, by introducing the double debonding failure criterion and high-temperature effect of asphalt paving construction, the finite element model was established. Thirdly, the temperature measurement result was presented, and the simulation results were compared with the test results from the load-deflection relationship, strain distribution, and failure modes. Finally, the calculation model of debonding bearing capacity and interface debonding strain were proposed based on the experimental and the numerical results.

In this study, the interfacial bonding behavior of CFRPreinforced concrete beams was investigated, especially the effect on the mechanical properties after high-temperature action of asphalt paving construction. It can be applied to the performance evaluation of the CFRP-strengthened bridge under the coupling effect of asphalt high temperature and traffic load. Experimental test and numerical simulation of CFRP-reinforced concrete beam were carried out, and the problems of nonlinearity and interface softening were especially considered in the finite element analysis. Besides, the parametric study of CFRP-strengthened structure can be applied to predict the debonding bearing capacity of strengthened structure after high-temperature action.

\section{Experimental Study}

2.1. Specimen Design. The test specimens were designed after the force analysis of the box girder section according to the load combination. The designed specimens can accurately simulate the stress state of the box girder roof, and the specimens can be used to evaluate the reinforcement effect of the CFRP plate after high-temperature action of asphalt paving construction. The specimens were $4 \mathrm{~m}$ long, $0.65 \mathrm{~m}$ width, and $0.28 \mathrm{~m}$ height. The specimens were strengthened with three pieces of CFRP plates. The cross section and the reinforcement of the CFRP plates are shown in Figure 2.

To obtain the stain distribution of the CFRP plate, the strain gauges were pasted on the surface of the CFRP plates. Related studies have shown that the strains of the CFRP plate change significantly at both ends and change smoothly near the midspan $[17,18]$. Therefore, the strain gauges should be closely arranged at both ends of the CFRP plate and sparsely arranged near the midspan position. This strain gauges arrangement law was also applied in this test. Specially, the strain gauges were arranged closely and staggered in the range of $200 \mathrm{~mm}$ at both ends of the CFRP plate, and the strain gauges in the range of $1400 \mathrm{~mm}$ on both sides of the midspan are arranged at intervals of $200 \mathrm{~mm}$. The arrangement scheme of the stain gauges is presented in Figure 2 as well.

For simulating the actual condition of asphalt paving process, the $50 \mathrm{~mm}$ thick SMA (stone mastic asphalt) wear layer was paved on the specimens. To reduce the influence of the high-temperature effect of asphalt on the CFRP plate, two kinds of the deck paving scheme were designed. For Scheme A shown in Figure 3(a), a heat insulation layer and a waterproof layer were arranged on the box girder roof. The deck paving Scheme B using epoxy resin mortar layer is also proposed as shown in Figure 3(b).

According to the two asphalt paving schemes, two types of specimen are designed separately, which are the specimens FX-1 to FX-3 and specimens FY-1 to FY-2 in Group A. 


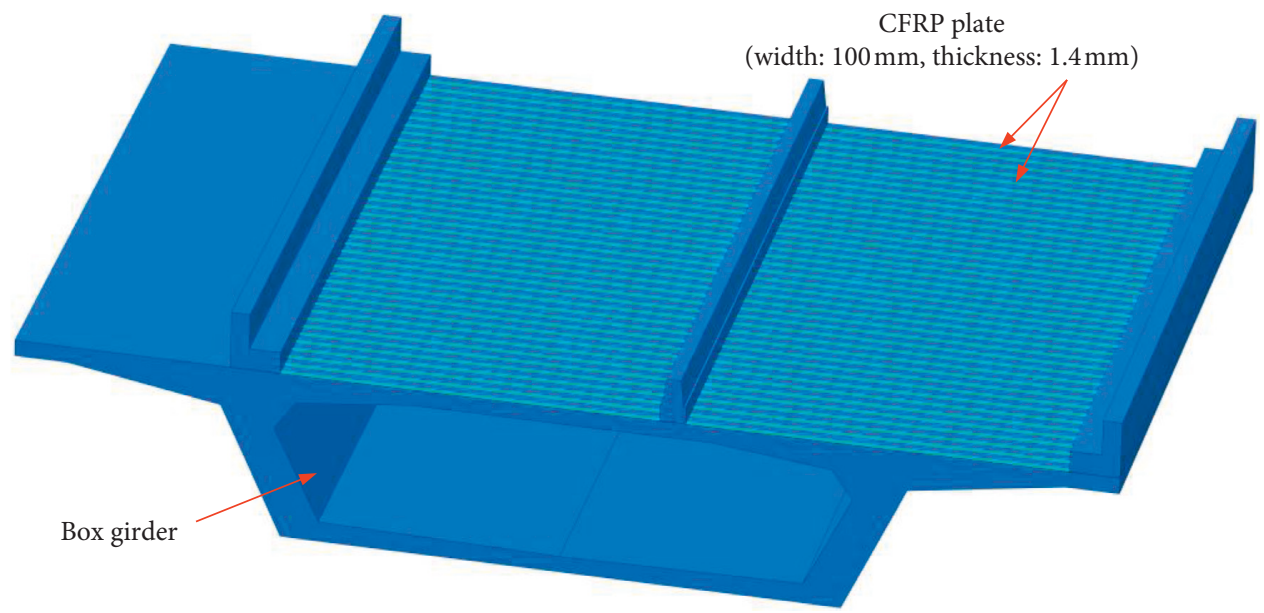

FIGURE 1: Reinforcement scheme of the bridge roof.
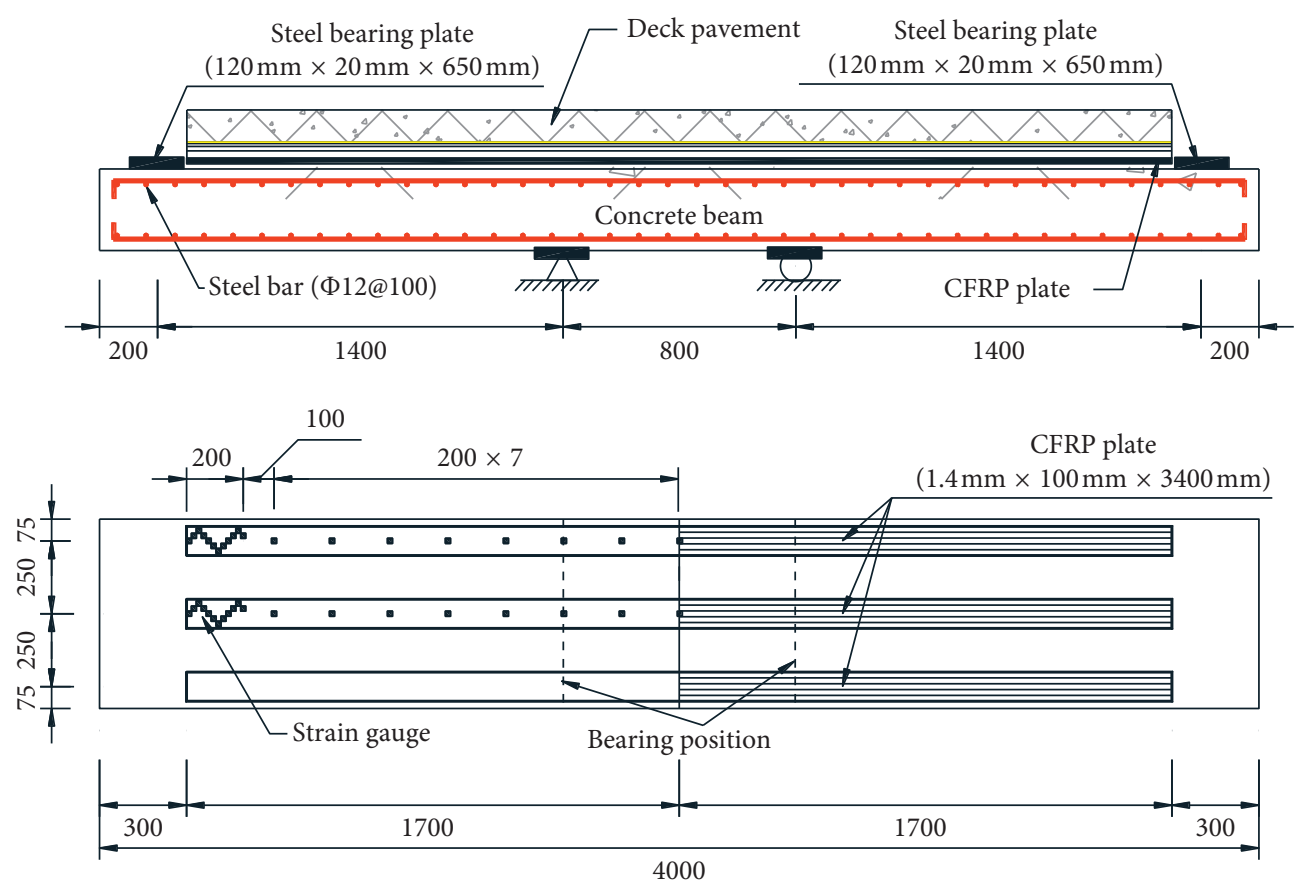

Figure 2: Dimensions of the specimen and arrangement scheme of stain gauges (unit: $\mathrm{mm}$ ).

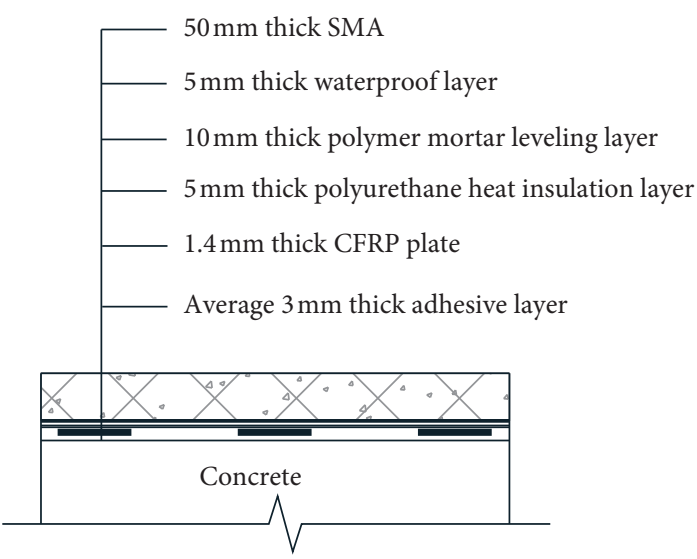

(a)

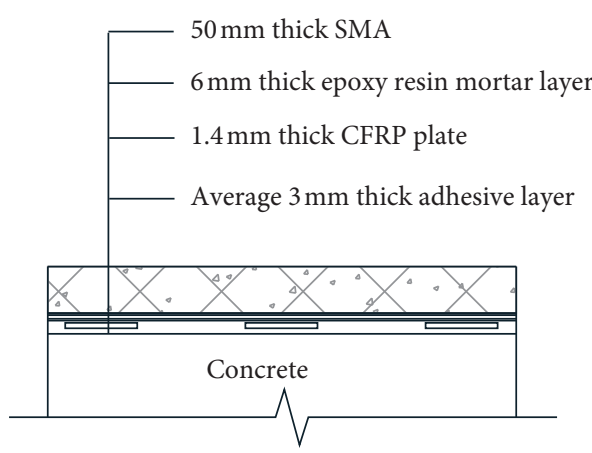

(b)

FIgURE 3: Deck paving schemes. (a) Scheme A. (b) Scheme B. 
In this test, the specimen FDBL is the control specimen for obtaining the ultimate bearing capacity of concrete beam and comparing the failure modes with the CFRP-reinforced specimens. The specimens in Group A are used to compare the thermal insulation performance of the deck paving schemes which is shown in Figure 3. These specimens can be divided into two series: FX series and FY series. Both series of specimens are strengthened with CFRP plate, and the difference between them is the deck paving scheme. Table 1 shows the classification and parameters of various types of specimens.

The grade of the concrete is C45, the grade of the steel bar is HRB 400, and the type of the adhesive is K-801. The properties of materials used in this test are listed in Table 2.

2.2. Experiment Setup. The specimens for test were prepared as designed. The CFRP plates were pasted on the specimen after they were maintained, and then the SMA layer was paved on the surface of the specimen.

The temperatures at different locations of the asphalt layer and the CFRP plates were measured. The locations of the thermocouple detector are shown in Figure 4(a). The thermocouple detectors were embedded in the construction site, as shown in Figure 4(b). The temperatures of the upper, middle, and lower surfaces of the asphalt layer were tested during the paving process. The temperatures of the upper side and lower side of the CFRP plate were measured as well.

In the loading test for specimens, the load was performed by four-point loading. The arrangements of the test device and specimen are shown in Figure 5. A 30 tons hydraulic jack was applied in this test for the simultaneous loading. The load applied on the specimen was increased step by step as shown in Figure 6. The maximum load applied on the specimen was based on the yield of steel bar, concrete fracture, or the debonding of the CFRP plate.

\section{Numerical Simulation}

3.1. Bond-Slip Model with Double Debonding Failure Criterion. The double debonding failure criterion proposed by $\mathrm{Lu}$ et al. $[17,18]$ was introduced to the definition of the FRP plate and concrete interface element. The basic principle of the double debonding failure criterion adopted in this paper is as follows.

3.1.1. Bond-Slip Criterion I. It is the crack-free debonding criterion. For this kind of criterion, the slip field is considered to be relatively uniform. This model is suitable for the case where the flexural crack is far from the CFRP plateconcrete interface and the concrete element is not cracked.

3.1.2. Bond-Slip Criterion II. It is the crack debonding criterion. Under this circumstance, the slip field of the interface element has a phenomenon of slip concentration. The scope of application of the model is that the crack exists in the concrete element that is connected to the interface element with crack.
The interface bond-slip relationship and the debonding failure criterions mentioned above were applied to the FRPconcrete interface element. Figure 7 shows the interface bond-slip models I and II. And the formulas of bond-slip models I and II are as follows:

Bond-slip model I:

$$
\begin{cases}\tau=\tau_{\max } \sqrt{\frac{s}{s_{0}}}, & s \leq s_{0}, \\ \tau=\tau_{\max } e^{-\alpha\left(\left(s / s_{0}\right)-1\right)}, & s>s_{0} .\end{cases}
$$

Bond-slip model II:

$$
\begin{cases}\tau=\tau_{\max } \sqrt{\frac{\mathcal{s}}{s_{0}}}, & s \leq s_{0}, \\ \tau=0, & s>s_{0},\end{cases}
$$

where $\tau$ is the shear stress and $s$ is the interface slip, $s_{0}$ is the initial slip, $\tau_{\max }$ is the maximum shear stress corresponding to the interface slip peak, and $\alpha$ is a regression coefficient.

3.2. Establishment of Finite Element Model. The concrete element and the reinforcement element are all defined by a four-node plane stress element, the concrete element adopts Element 3, and the reinforcement element adopts Element 143. The size of the concrete element is of ordinary size, and its size adopted in this article is $25 \mathrm{~mm}$. The CFRP plate element is defined by the planar truss element Element 9. The elements for establishing the finite element model are shown in Figure 8.

The constitutive relationship of concrete is defined by the elastoplastic concrete model in MSC.MARC. The yield surface model suggested by Buyukozturk [19] is adopted, and its expression is as follows:

$$
f=\beta_{b} \sqrt{3} \bar{\sigma} I_{1}+r_{b} I_{1}^{2}+3 J_{2}-\bar{\sigma}^{2},
$$

where $f$ is the yield surface, $\bar{\sigma}$ is the equivalent stress, $I_{1}$ is the first stress invariant, $J_{2}$ is the second deviatoric stress invariant, $\beta_{b}$ and $r_{b}$ are the correction coefficients, and $\beta_{b}$ and $r_{b}$ are suggested to take $\sqrt{3}$ and 0.2 , respectively.

Although the slip of the steel bar has a certain degree of influence on the stiffness of the member, it has little effect on the debonding bearing capacity of the CFRP plate. Thus, in order to simplify the calculation, it is assumed that the element nodes are shared between the concrete element and the steel bar element. The slip between the two types of element is not considered in this article, and the steel bar adopts an ideal elastoplastic constitutive model.

The CFRP plate was defined by both the fracture material model and the linear elastic model. When the stress of the CFRP plate reaches the fracture stress, the linear elastic model is adopted. And when the fracture stress is reached, the fracture of the CFRP plate occurs, and the stress 
TABle 1: Classification of specimens for test.

\begin{tabular}{|c|c|c|c|c|}
\hline \multicolumn{2}{|c|}{ Serial number } & Reinforcement measure & Deck paving scheme & Purpose \\
\hline \multirow[t]{2}{*}{ FDBL } & & None & None & Contrast specimen \\
\hline & $\begin{array}{l}\text { FY-1 } \\
\text { FY-2 }\end{array}$ & CFRP plate & Scheme A & \\
\hline \multirow[t]{2}{*}{ Group A } & FX-1 & & & Comparison of the thermal insulation performance \\
\hline & $\begin{array}{l}\text { FX-2 } \\
\text { FX-3 }\end{array}$ & CFRP plate & Scheme B & \\
\hline
\end{tabular}

TABLE 2: Material properties.

\begin{tabular}{|c|c|c|}
\hline Material & Performance parameter & Parameter value \\
\hline \multirow{4}{*}{ CFRP plate } & Section size $(\mathrm{mm} \times \mathrm{mm})$ & $100 \times 1.4$ \\
\hline & Tensile strength $(\mathrm{MPa})$ & $2300 \sim 2400$ \\
\hline & Tensile modulus (GPa) & $150 \sim 155$ \\
\hline & Elongation at break (\%) & $1.4 \sim 1.42$ \\
\hline \multirow{4}{*}{ Concrete (C45) } & Elastic modulus (MPa) & $3.35 \times 10^{4}$ \\
\hline & $\begin{array}{l}\text { Standard value of concrete axial compressive strength } \\
\qquad(\mathrm{MPa})\end{array}$ & 29.6 \\
\hline & $\begin{array}{l}\text { Standard value of concrete axial tensile strength } \\
\qquad(\mathrm{MPa})\end{array}$ & 2.51 \\
\hline & Poisson's ratio & 0.2 \\
\hline \multirow{4}{*}{ Steel Bar (HRB 400) } & Nominal diameter $(\mathrm{mm})$ & $25 \sim 26$ \\
\hline & Elastic modulus (MPa) & $2500 \sim 2600$ \\
\hline & Tensile strength standard value (MPa) & $30 \sim 32$ \\
\hline & Compressive strength standard value $(\mathrm{MPa})$ & $70 \sim 75$ \\
\hline \multirow{4}{*}{ Adhesive (K-801) } & Tensile strength $(\mathrm{MPa})$ & $6 \sim 50$ \\
\hline & Tensile modulus of elasticity ( $\mathrm{MPa})$ & $2.0 \times 10^{5}$ \\
\hline & Bending strength $(\mathrm{MPa})$ & 400 \\
\hline & Compressive strength $(\mathrm{MPa})$ & 400 \\
\hline
\end{tabular}

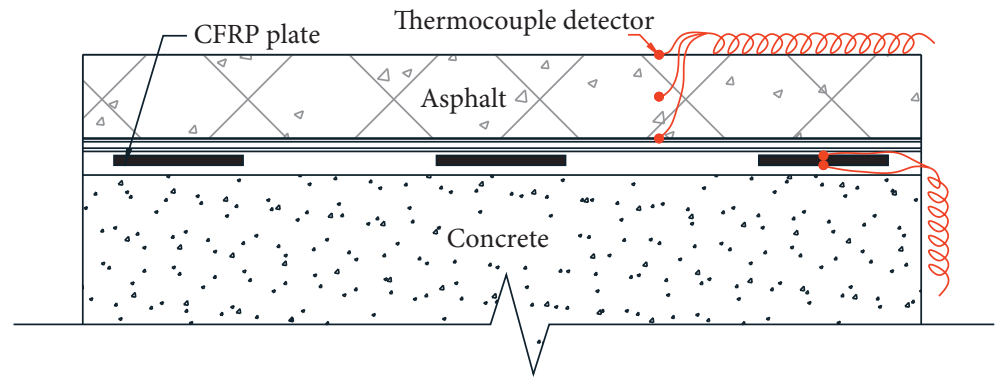

(a)

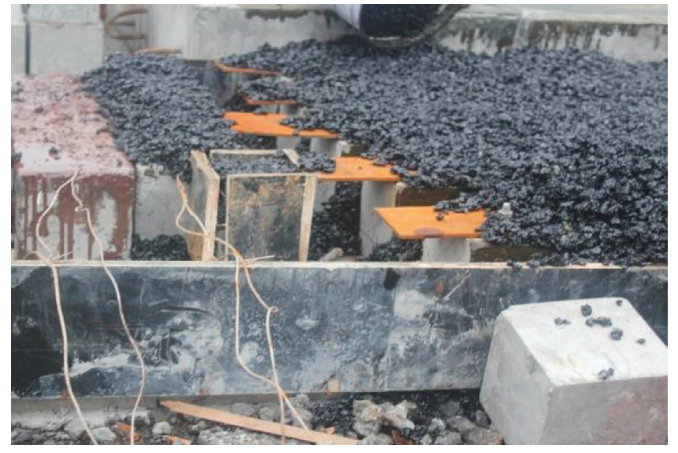

(b)

Figure 4: Temperature test with thermocouple detector. (a) Locations of the thermocouple detector. (b) Thermocouple detector in the site.

immediately decreases to zero; that is, the fracture material model is adopted.

The width of crack can be estimated by using the smeared crack model for concrete with normal size elements in FEA, and the debonding failure near the crack caused by the slip concentration can be estimated accurately by introducing the double debonding failure criterion.

\section{Investigation Results and Analysis}

4.1. Temperature Measurement Result. Figure 9 presents the temperature change curves measured at different positions.
It can be seen from Figure 9 that the maximum temperature of the asphalt surface layer can reach to $172^{\circ} \mathrm{C}$. And after 60 minutes, the temperature of different positions of the asphalt layer can be recovered to about $65^{\circ} \mathrm{C}$. For the temperature change curve of the CFRP plate, the temperature curve of the upper surface changes greatly. For the deck paving Scheme A, the maximum temperatures on the upper and lower sides of the CFRP plate are $72.2^{\circ} \mathrm{C}$ and $60.7^{\circ} \mathrm{C}$, respectively. The maximum temperatures of Scheme $\mathrm{B}$ are $72.7^{\circ} \mathrm{C}$ and $64.8^{\circ} \mathrm{C}$, respectively. From the comparison of the two deck paving schemes, the temperature change rate of the CFRP plate in Scheme B is relatively fast. The overall 


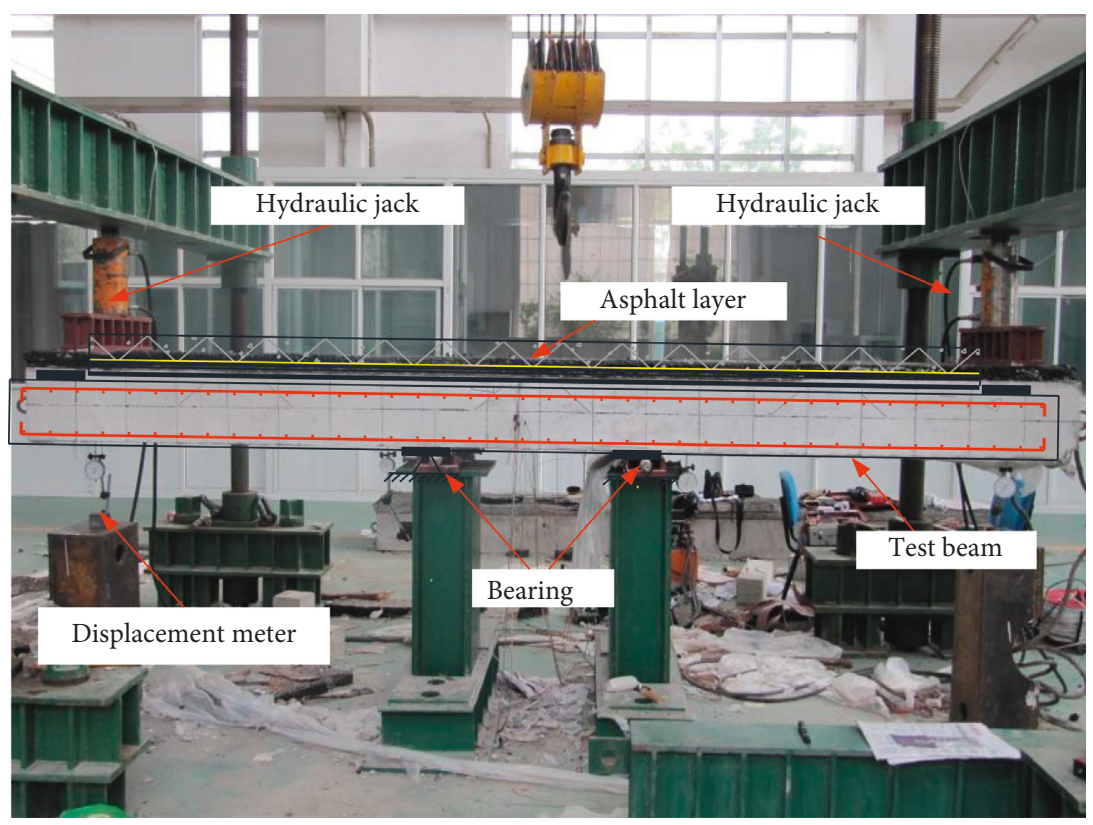

FIgURE 5: Loading device for experiment.

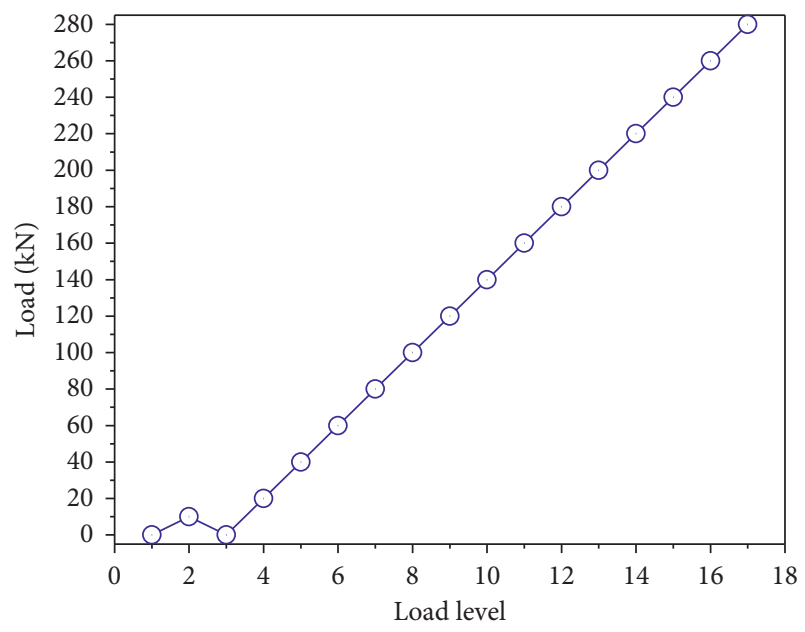

Figure 6: Test loading step.

structure of Scheme B is relatively sensitive to temperature transfer. The temperature of the CFRP plate can be recovered in a relatively short period of time, and the CFRP plate can reach a temperature stable state after temperature transfer. It can be concluded that it is feasible to use epoxy resin mortar in Scheme B instead of the original deck pavement in Scheme A.

4.2. Comparison of Experimental and Simulation Results. The finite element model was established according to the double debonding criterion and the constitutive models of different materials. The mechanical behavior of the CFRP plate-reinforced concrete member after high-temperature action of asphalt paving construction was simulated. The comparison discussion of the FEA results and test results is as follows.

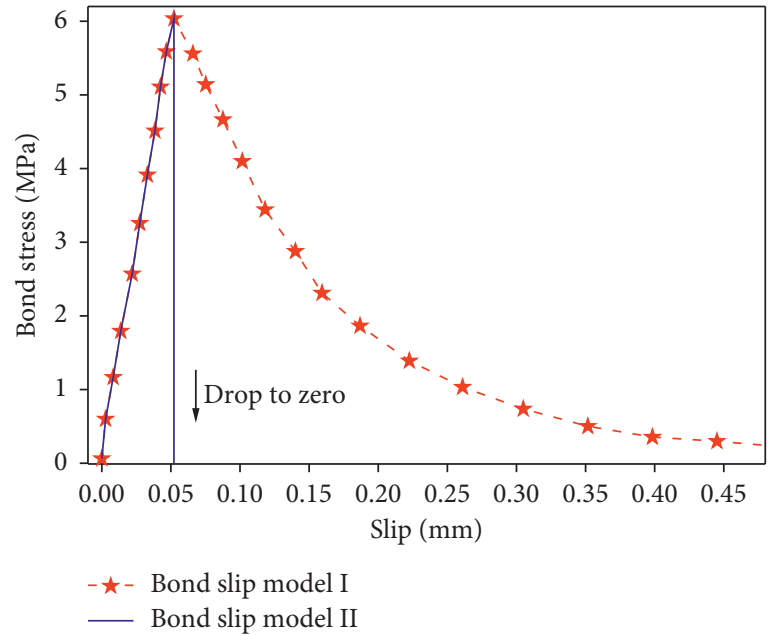

FIGURE 7: Interface bond-slip relationship of models I and II.

4.2.1. Load-Deflection Relationship. Figure 10 presents the comparison between the test results and the finite element results of load-deflection relationship. The debonding failure near the cracks caused by the slip concentration was considered, and the debonding bearing capacity was estimated well. It can be seen from Figure 10 that the load-deflection curves of specimen FDBL basically coincided with that of specimens in Group A.

Compared with the specimen FDBL and the specimens in GROUP A, the specimens in GROUP A are strengthened by the CFRP plates. The CFRP plates can share the tensile stress with the reinforce bar, and the bonding shear force in the interface of the CFRP plates and concrete can reduce the crack width of the specimen in which the stiffness of the specimen can be greatly improved. Therefore, the specimens strengthened by the CFRP plates will not be destroyed immediately. 


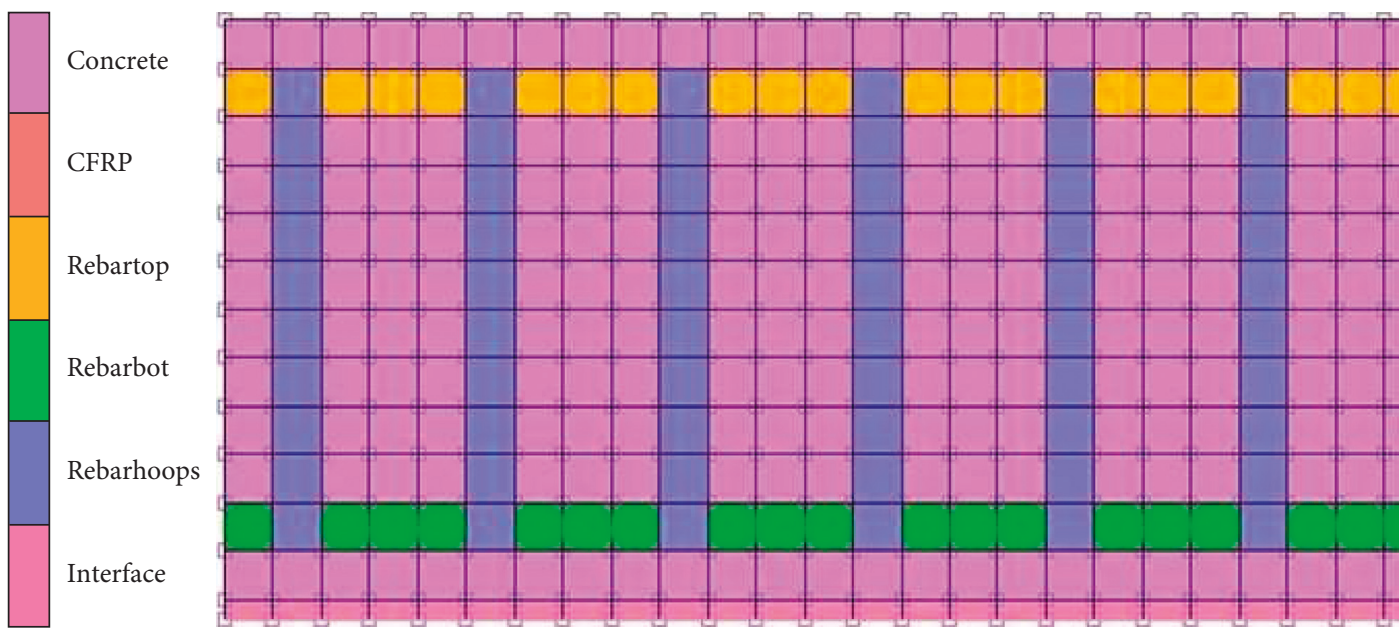

Figure 8: Element types of the finite element model.

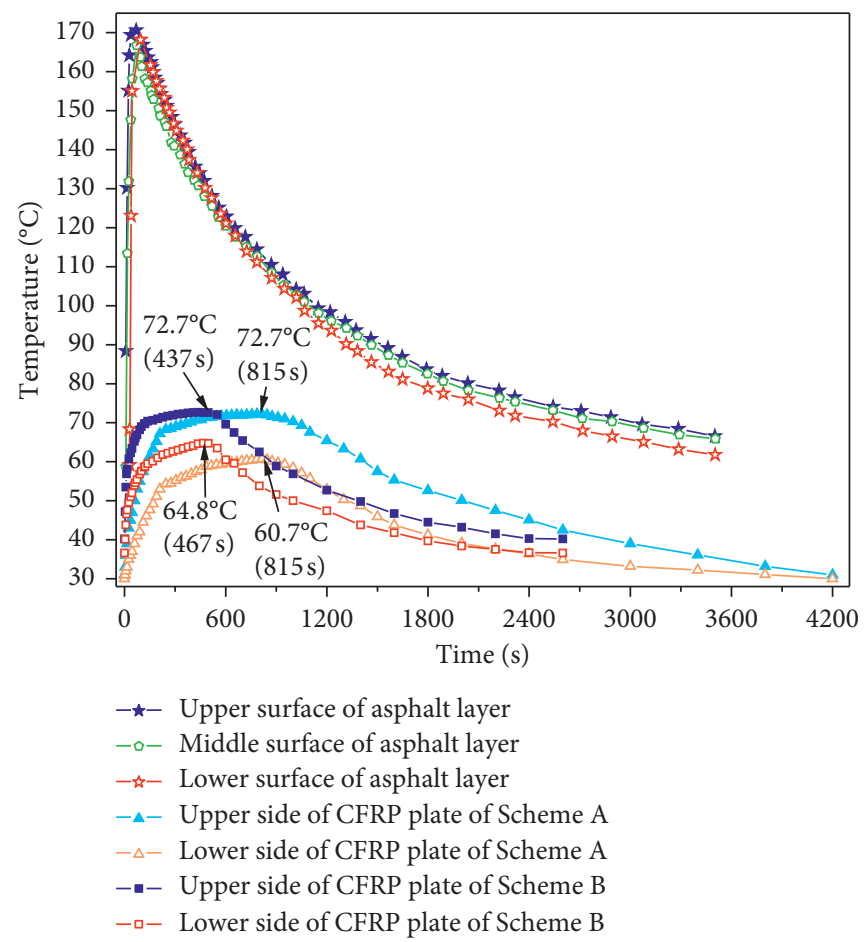

FIgURE 9: Temperature change curve of asphalt layer and CFRP plate.

When the first crack occurs in the pure flexural section of the specimen, the concrete in the tension zone will be out of service. For the specimen FDBL, the tensile stress in the concrete was borne by the steel bar. For the specimens in Group A, the tensile stress in the concrete was shared by the CFRP plate and the steel bar. The introduction of the CFRP plates delayed the cracking speed of the section, and the rate of rise of the neutral axis was also slowed down.

4.2.2. Strain Distribution of CFRP Plate. The simulation result of the CFRP plate strain is shown in Figure 11. It can be seen from Figure 11 that no cracks appear on the interface between the CFRP plate and concrete when the load is at a relatively small stage $(P=120 \mathrm{kN})$, the CFRP plate and the concrete are better bonded, and the strain from the midspan to the beam end is decreasing. When the load reached $140 \mathrm{kN}$, the initial debonding occurred at the interface of the CFRP plate and concrete near the midspan. The slope of the strain curve in the debonding zone rapidly decreased, and the curve was roughly $S$ shaped. The interfacial frictional shear in the debonding zone caused the maximum strain on the CFRP plate to continue to increase, and the local slip caused by the expansion of the crack width becomes the main cause of 


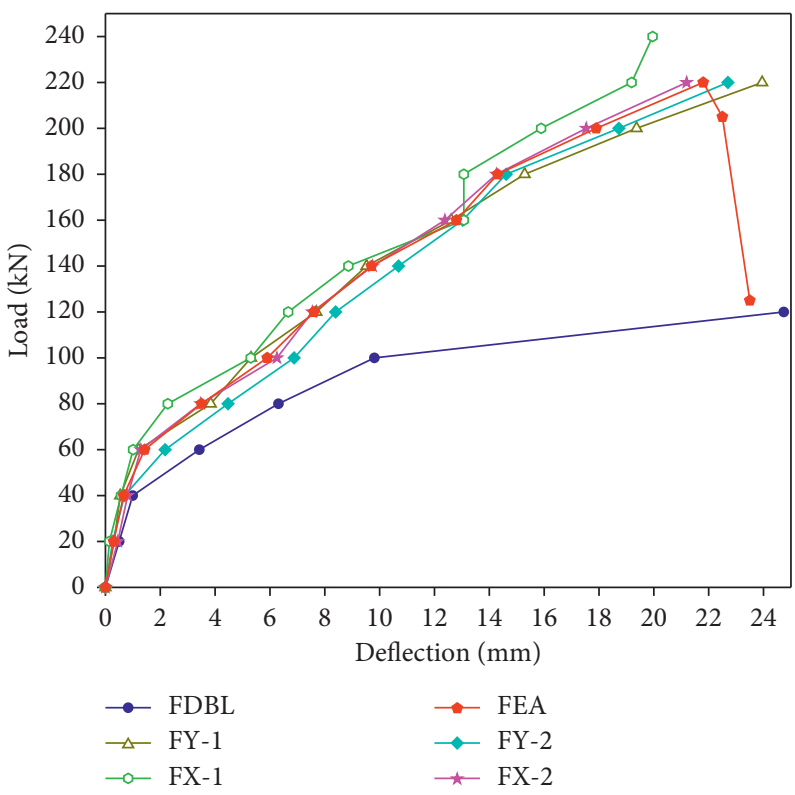

FIgURE 10: Comparison of load-deflection curve of the FEA results and test results.

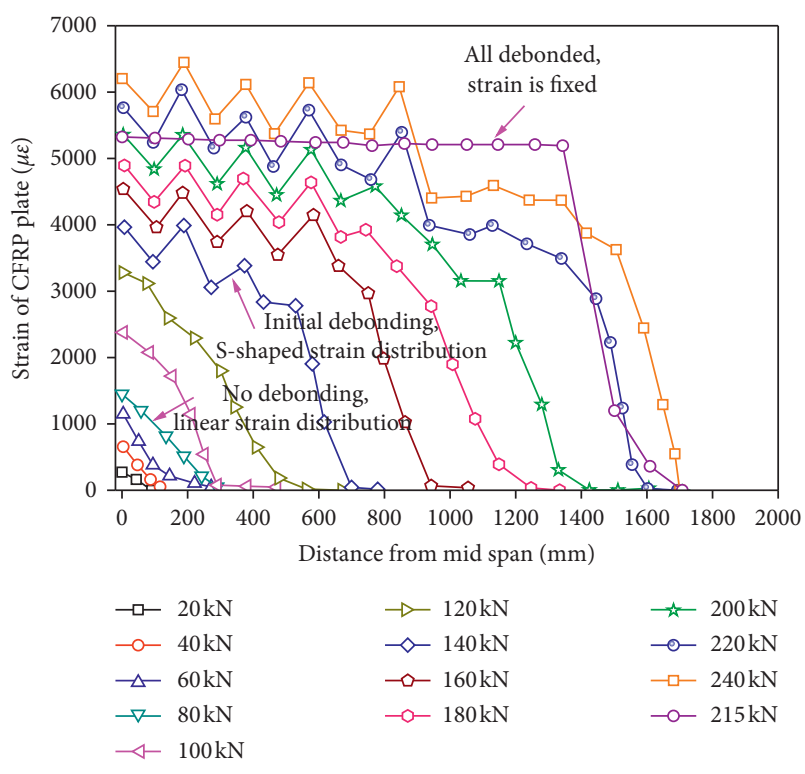

FIGURE 11: Finite element simulation results of CFRP plate strain at different load levels.

the interface slip. As the length of the debonding zone increased, the S-shaped strain distribution curve extended to the free end of the CFRP plate. Finally, before the CFRP plate debonding occurred $(P=240 \mathrm{kN})$, the interfacial strain was mainly the interface slip caused by the crack propagation. When the CFRP plate debonding failure occurred, the stress of the CFRP plate dropped immediately.

Figure 12 shows the strain of the CFRP plate measured during the tests. It can be seen from the comparison between Figures 11 and 12 that the variation characteristic of the strain distribution of the CFRP plate obtained by the simulation is similar to that achieved by the tests.
4.2.3. Crack Propagation. In order to improve the calculation rate of the finite element model, half of the test beams were simulated considering the structural symmetry of the test beam and the corresponding boundary conditions. Figure 13 shows the FEA results of crack propagation of the specimen after interface element failure, and crack propagation of five representative load levels are selected. The right side of each graph represents the midspan position of the test beam, and the left side is the end of the specimen.

Many conclusions can be concluded from Figure 13. At a relatively small load level, microcracks appear at the midspan position, as shown in Figure 13(a). As the load level increases, the crack width and crack height increase, as shown in Figures 13(b) and 13(c). When the load is further increased, the crack distribution range extends toward the beam end, and the oblique crack gradually appears, as shown in Figures 13(d) and 13(e).

Figure 14 presents the test results of the specimen. It is observed that the cracks of the specimen in the test are mostly concentrated on both sides of the supports. Thus, the distribution of cracks within $400 \mathrm{~mm}$ on both sides of the supports is presented in this article.

It can be seen from Figures 13 and 14 that the crack propagation pattern of specimens after the test is in good agreement with the finite element simulation results. Taking the crack distribution shape of the specimens FY2, FX-1, and FX-2 as an example, the crack at the position of the midspan is mostly a vertical crack, and the cracks near the supports present as a slightly inclined dendritic shape.

From the analysis above, the debonding caused by the slip concentration near the crack can be better estimated by introducing the double debonding failure criterion. It can be seen from the results of the FEA that the debonding of the CFRP plate starts from the crack near the loading section, that is, the interface where the pure flexural zone 

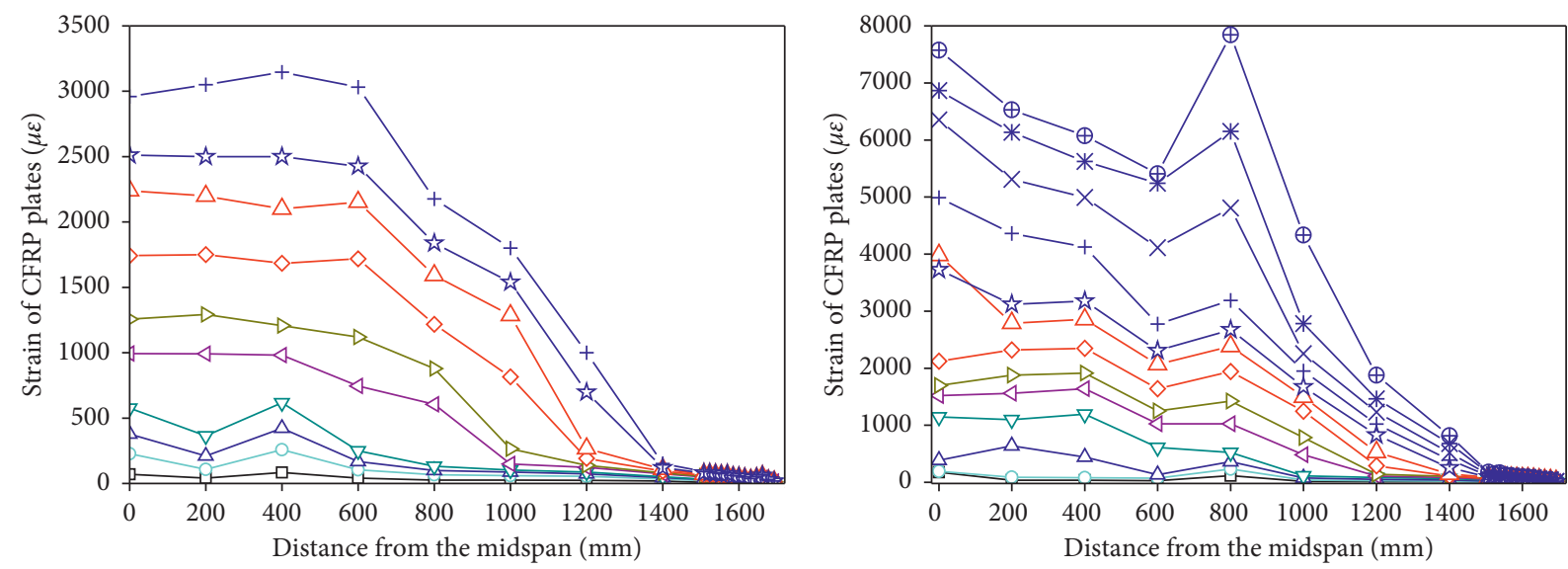

$$
\begin{aligned}
& \rightarrow-20 \mathrm{kN} \quad \rightarrow-120 \mathrm{kN} \\
& \neg-\circ 0 \mathrm{kN} \quad \smile 140 \mathrm{kN} \\
& \triangle-60 \mathrm{kN} \quad-\triangle-160 \mathrm{kN} \\
& \rightarrow-80 \mathrm{kN} \quad-\text { 许 }-180 \mathrm{kN} \\
& \triangleleft 100 \mathrm{kN} \quad-+-200 \mathrm{kN}
\end{aligned}
$$

(a)

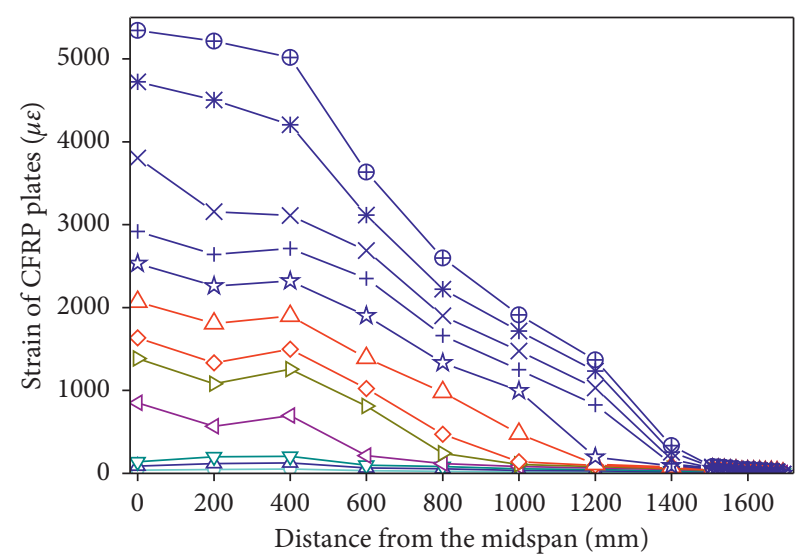

$\begin{array}{ll}-\multimap 20 \mathrm{kN} & -\triangle-140 \mathrm{kN} \\ -\triangle 40 \mathrm{kN} & -\longleftarrow-160 \mathrm{kN} \\ \neg-60 \mathrm{kN} & -+-180 \mathrm{kN} \\ \triangleleft-80 \mathrm{kN} & -\succ-200 \mathrm{kN} \\ \neg-100 \mathrm{kN} & -*-220 \mathrm{kN} \\ \neg-120 \mathrm{kN} & -\oplus-240 \mathrm{kN}\end{array}$

(c)

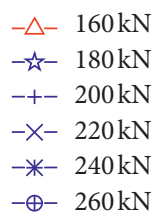

(b)

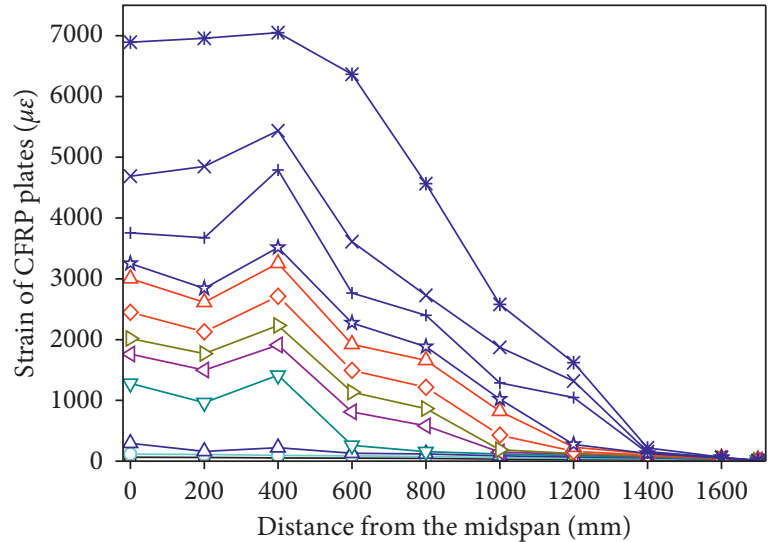
$\rightarrow-20 \mathrm{kN}$
$-\mathrm{O}-40 \mathrm{kN}$
$-\triangle-60 \mathrm{kN}$
$\rightarrow-80 \mathrm{kN}$
$\triangleleft 100 \mathrm{kN}$
$\rightarrow 120 \mathrm{kN}$

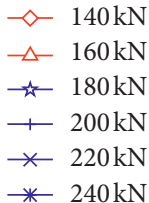

(d)

FIgURE 12: Continued. 


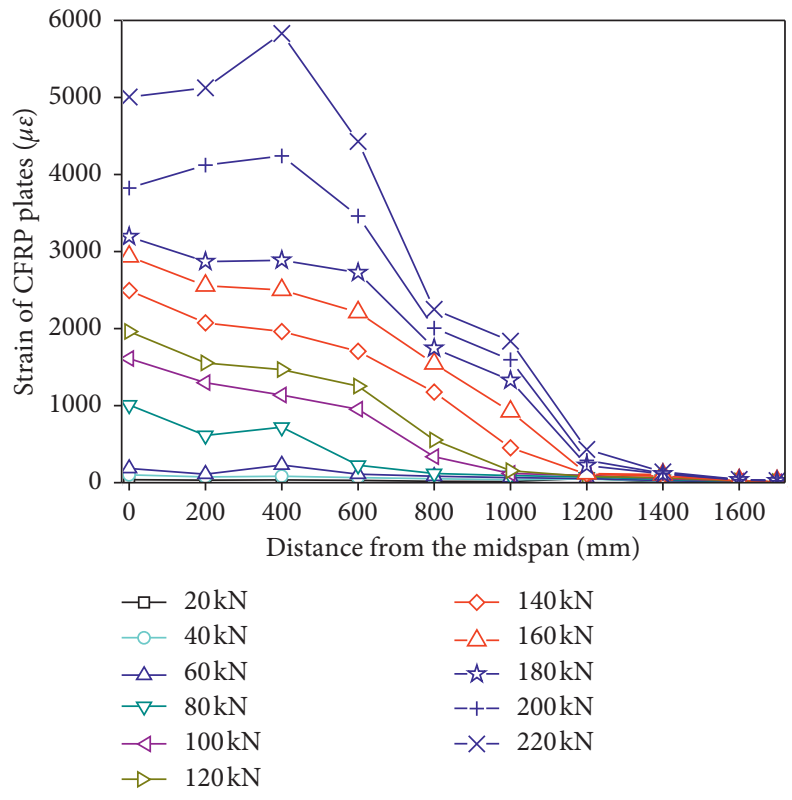

(e)

Figure 12: Test results of CFRP plate strain at different load levels. (a) Specimen FY-1. (b) Specimen FY-2. (c) Specimen FX-1. (d) Specimen FX-2. (e) Specimen FX-3.

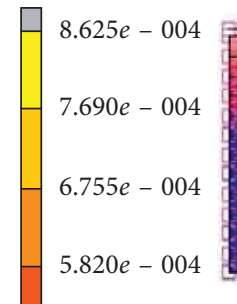

$\bigoplus \begin{gathered}1.662 e-003 \\ 1.481 e-003 \\ 1.300 e-003 \\ 1.119 e-003\end{gathered}$

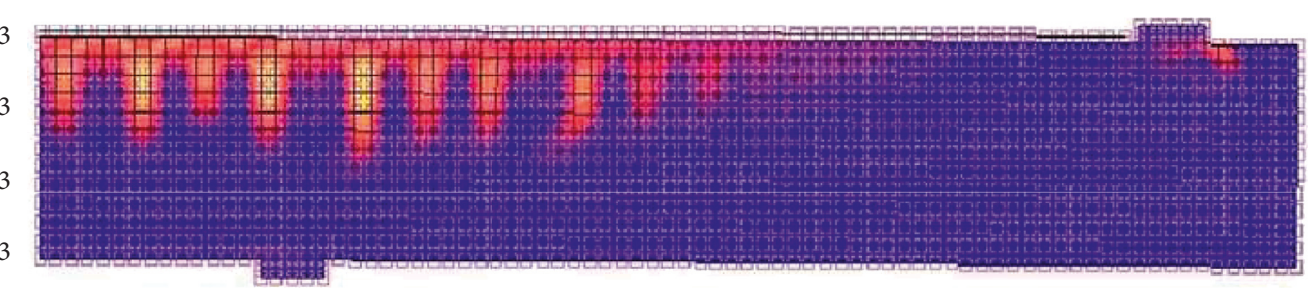

(b)

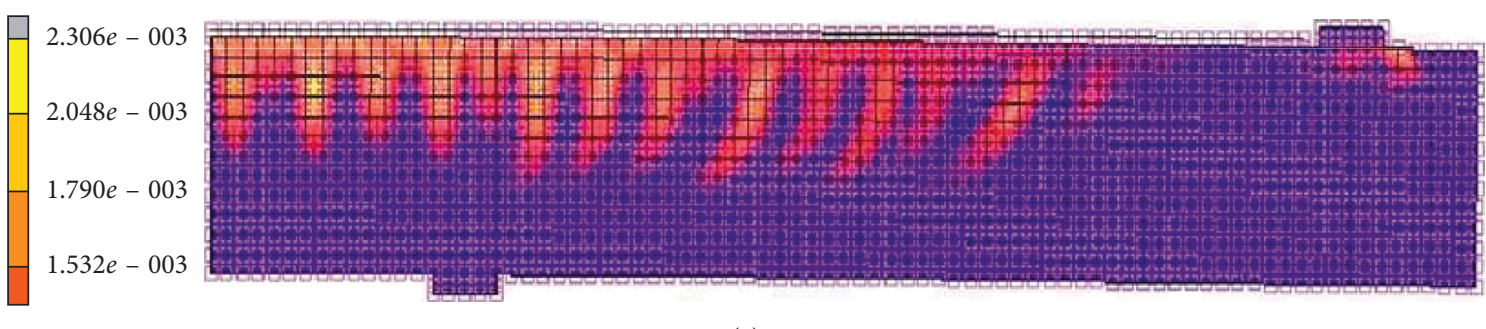

(c)

FIgure 13: Continued. 


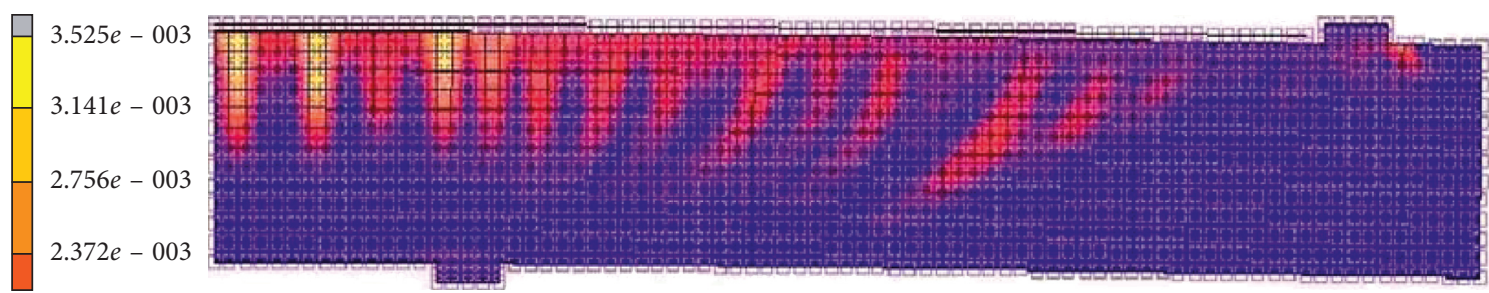

(d)

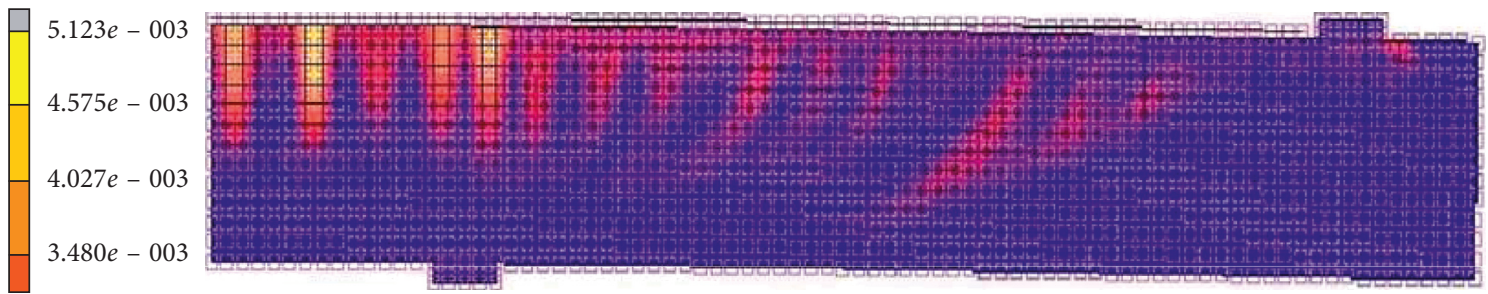

(e)

Figure 13: Crack propagation at different load levels simulated by finite element. (a) $P=20 \mathrm{kN}$. (b) $P=40 \mathrm{kN}$. (c) $P=80 \mathrm{kN}$. (d) $P=100 \mathrm{kN}$. (e) $P=120 \mathrm{kN}$.

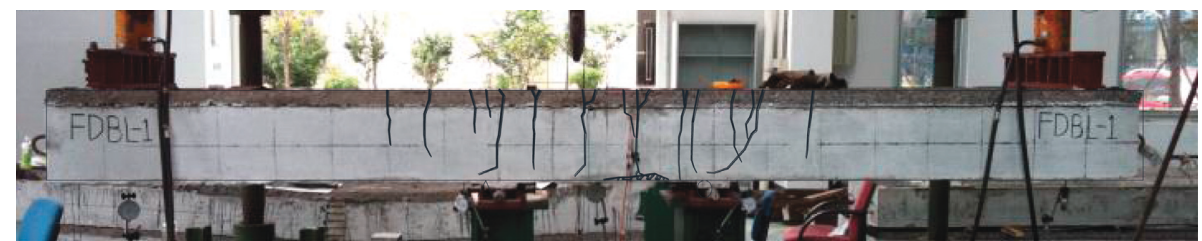

(a)

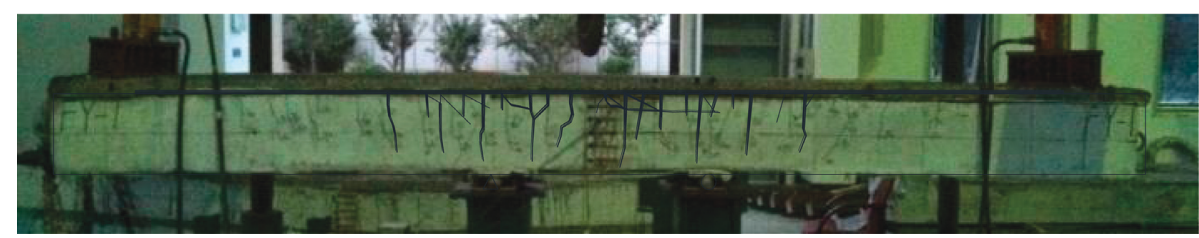

(b)

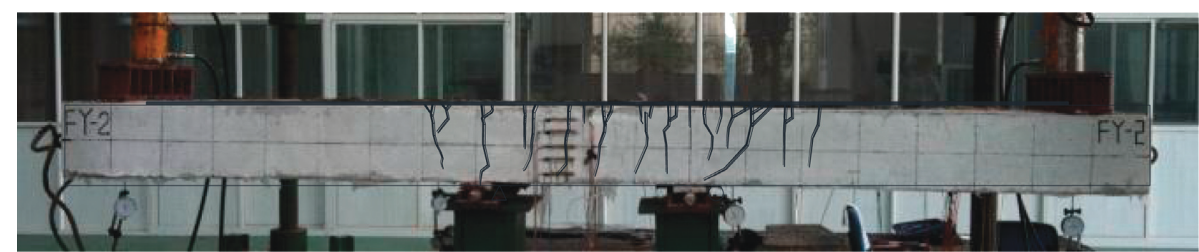

(c)

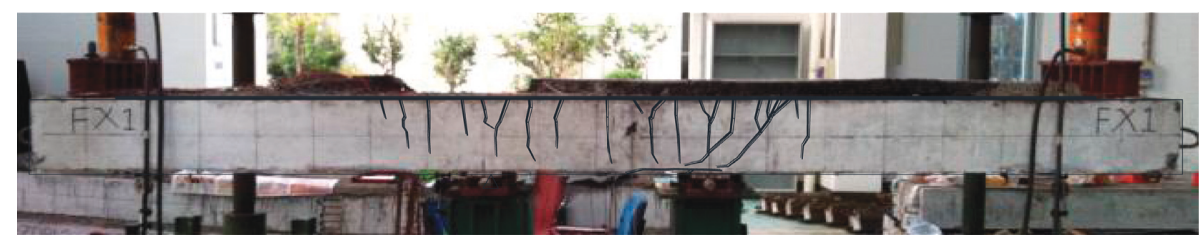

(d)

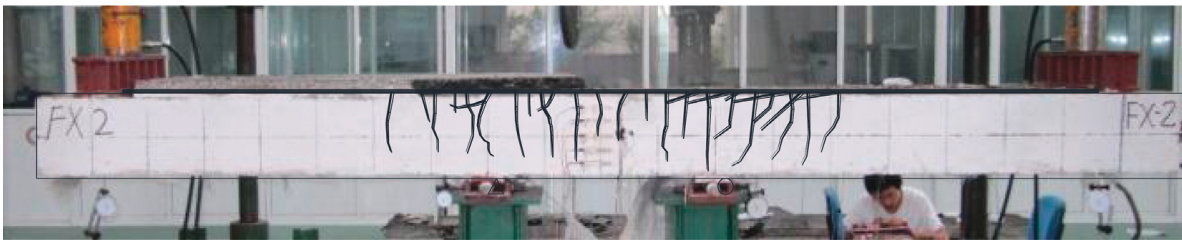

(e)

Figure 14: Continued. 


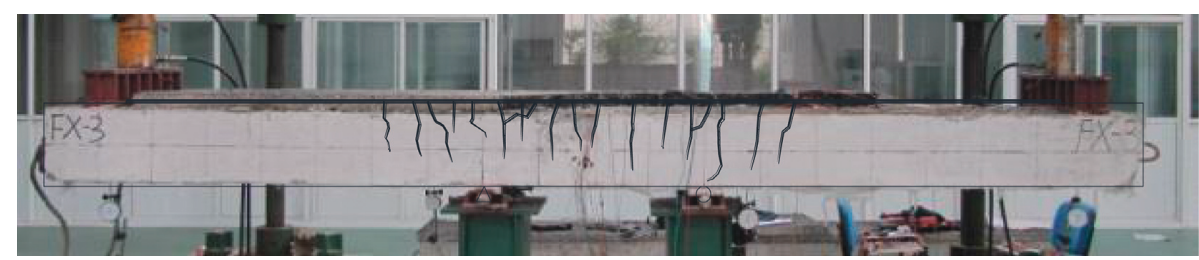

(f)

Figure 14: Crack propagation obtained in tests (unit: mm). (a) Specimen FDBL. (b) Specimen FY-1. (c) Specimen FY-2. (d) Specimen FX-1. (e) Specimen FX-2. (f) Specimen FX-3.

intersects the flexural shear zone. It is consistent with the failure mode of the specimen observed in the test. Therefore, the element used for FEA in this paper can simulate the intermediate crack debonding (IC debonding) failure more correctly.

\section{Parametric Study and Discussion}

The calculation of debonding bearing capacity is an important part of evaluating CFRP reinforcement structure. Based on the test results of the CFRP plate-reinforced concrete specimens, this paper proposed a model for calculating the debonding bearing capacity of the CFRP platereinforced concrete structure after the high-temperature action of asphalt paving construction.

The calculation model of the debonding bearing capacity of the CFRP plate-reinforced concrete beam is shown in Figure 15. The basic calculation formula of the CFRP platereinforced beam after high-temperature action can be derived.

Using the equilibrium condition of internal forces being of zero, the following equation can be obtained:

$$
f_{c} b x+\varepsilon_{s^{\prime}} E_{s^{\prime}} A_{s}=\varepsilon_{f, \text { debonding }} E_{f} A_{f}+\varepsilon_{s} E_{s} A_{s},
$$

where $\sum F_{x}$ is the sum of forces in the horizontal direction; $f_{\mathrm{c}}$ is the unit force of concrete in the compression zone; $b$ and $x$ are the width and height of the concrete in the compression zone, respectively; $\varepsilon_{s^{\prime}}, \varepsilon_{s}$, and $\varepsilon_{f \text {,debonding }}$ are the strains of the compressed reinforcement, the tension reinforcement, and the CFRP plate, respectively; $E_{s^{\prime}}, E_{s}$, and $E_{f}$ are the elastic models of the compressed reinforcement, the tension reinforcement, and the CFRP plate, respectively; and $A_{s^{\prime}}, A_{s}$, and $A_{f}$ are the cross-sectional areas of the compressed reinforcement, the tension reinforcement, and the CFRP plate, respectively.

From the equilibrium conditions of the sum of debonding moment and the moment of tension reinforcement of the section being zero, a balance equation can be obtained as follows:

$$
\begin{aligned}
M_{\mathrm{db}}= & f_{\mathrm{c}} b x\left(h_{0}-\frac{x}{2}\right)+\varepsilon_{s^{\prime}} E_{s^{\prime}} A_{s^{\prime}}\left(h_{0}-a_{s^{\prime}}\right) \\
& +\varepsilon_{f, \text { debonding }} E_{f} A_{f} a_{f},
\end{aligned}
$$

where $\sum M_{s}$ is the sum of the section flexural moments after taking the moment of the tensioned steel bar; $M_{\mathrm{db}}$ is the
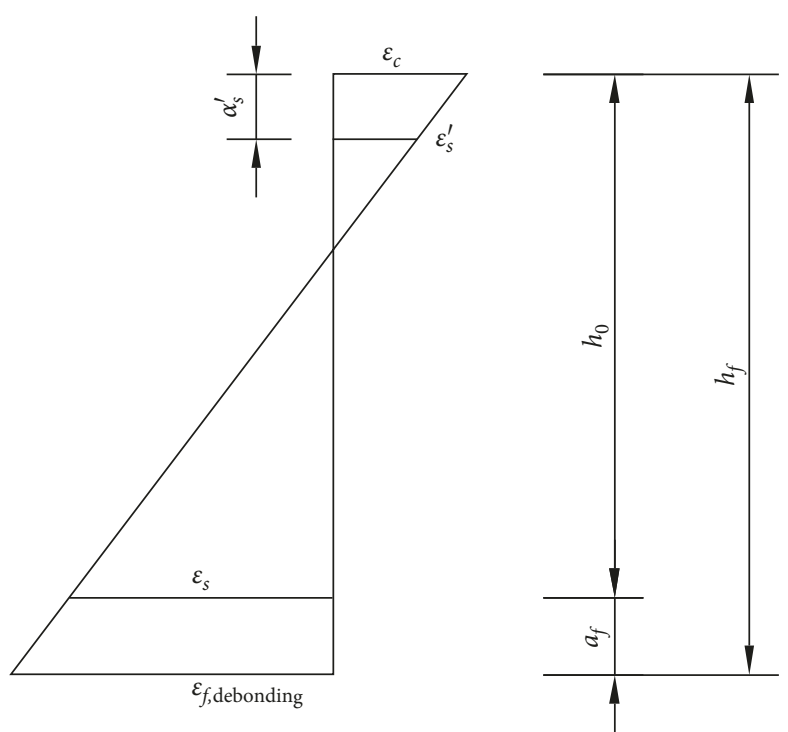

FIGURE 15: Schematic of debonding bearing capacity computation of CFRP plate-reinforced concrete beam.

debonding moment of the CFRP plate-reinforced beam; $h_{0}$ is the effective height of the section; $x$ is the height of the concrete compression zone; $a_{s^{\prime}}$ is the distance from the resultant point of the compression reinforcement to the edge of the compression zone; and $a_{f}$ is the distance from the resultant point of the CFRP plate to the edge of the tension zone.

For the equilibrium conditions that the sum of debonding moment and the moment of the compressed steel bar of the section is zero, the following balance equation can be obtained:

$$
\begin{aligned}
M_{\mathrm{db}}= & f_{\mathrm{c}} b x\left(h_{0}-a_{s^{\prime}}\right)+\varepsilon_{s} E_{s} A_{s}\left(h_{0}-a_{s^{\prime}}\right) \\
& +\varepsilon_{f, \text { debonding }} E_{f} A_{f}\left(h_{f}-a_{s^{\prime}}\right),
\end{aligned}
$$

where $\sum M_{s^{\prime}}$ is the sum of the section flexural moments after taking the moment of the compression steel bar and $h_{f}$ is the effective height of the CFRP plate.

It can be seen from equations (4)-(6) that the key to obtain the debonding bearing capacity of the CFRP plate is to obtain the strain value of the CFRP plate $\varepsilon_{f \text {,debonding. The }}$ calculation method for obtaining the strain of the CFRP plate will be further introduced in this article.

When the IC debonding failure of the CFRP plate occurs in the test beam, the interface bond stress distribution obtained by finite element simulation is shown in Figure 16, 


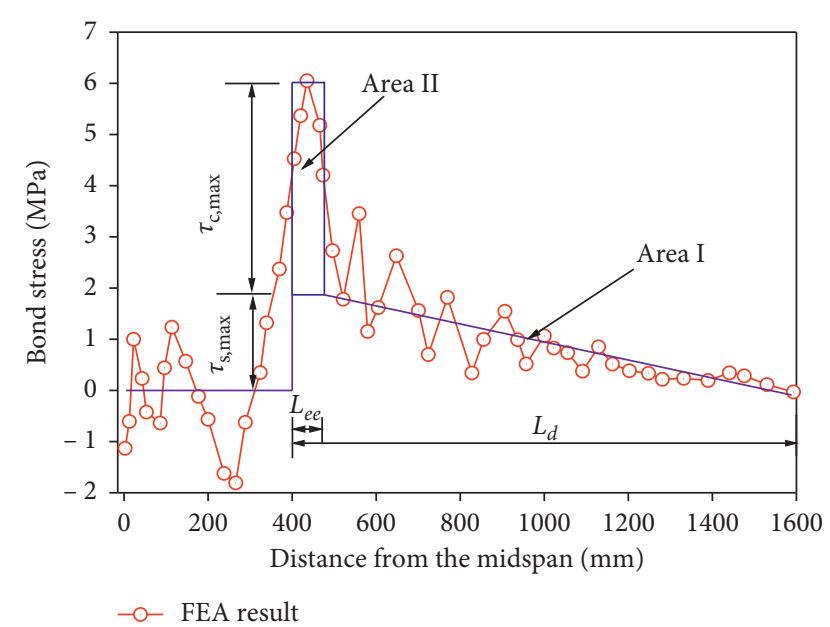

FIgURE 16: Distribution of interface bond stress during IC debonding failure.

where $L_{e e}$ is the length of interface bonding stress caused by cracking and $L_{d}$ is the length from the end section of the CFRP plate to the section that the maximum flexural moment may occur. $\tau_{c, \max }$ and $\tau_{\mathrm{s}, \max }$ are the maximum interface bonding stress caused by flexural crack and shear force, respectively.

A simplified interface stress distribution model proposed by Lu et al. [17] is introduced to obtain the strain value of the CFRP plate. It can be seen from Figure 16 that there is a phenomenon of local fluctuation in the interface bond stress curve. The curve can be simplified by smoothing. The flexural shear segment of the curve can be composed of a rectangular stress zone Area I and a triangular stress zone Area II, and the value of the pure flexural segment of the curve can be regarded as zero. In this figure, Area I represents the interface bonding stress caused by the shear force, and Area II represents the local interface bonding stress caused by the cracking.

For the CFRP plate-reinforced beams with an interface behavior similar to the "Bond-Slip Criterion II" near the curved crack position, the formula proposed by Yuan et al. [20] can be applied to calculate the length of bond stress, and the formula is as follows:

$$
L_{e e}=\sqrt{\frac{4 E_{f} t_{f}}{\tau_{\max } / s_{0}}}=0.183 \sqrt{E_{f} t_{f}},
$$

where $s_{0}$ is the slip corresponding to the peak shear stress and $\tau_{\max }$ is the peak shear stress.

In practice, the cemented layer will penetrate into the concrete layer and will produce chemical bonding and the bonding ability of the interface will be improved. In addition, the uneven distribution of the internal stress of the concrete due to the bonding width of the CFRP sheet also needs to be taken into consideration. The shear stress peak calculation formula proposed by Bencardino et al. [21] is introduced into the interface bond-slip model, and the formula is as follows:

$$
\begin{aligned}
\tau_{\max } & =\alpha_{a} \cdot \beta_{\mathrm{w}} \cdot f_{\mathrm{ctm}}, \\
\beta_{\mathrm{w}} & =\sqrt{\frac{2-b_{f} / b_{c}}{1+b_{f} / b_{c}}}
\end{aligned}
$$

where $\alpha_{a}$ is the bond enhancement coefficient, $\beta_{\mathrm{w}}$ is the width ratio coefficient, $f_{\mathrm{ctm}}$ is the tensile strength of concrete surface, $b_{f}$ is the bonding width of the CFRP plate, and $b_{c}$ is the width of the concrete specimen. Based on the experiment results in the previous study [22] that $\tau_{\max }$ can be taken as $6 \mathrm{MPa}$, and the value of $\alpha_{a}$ is recommended to be equal to 1.688 .

According to the equilibrium condition of forces, the maximum axial force of the CFRP plate when the IC debonding occurred can be calculated by the following formula:

$$
\begin{array}{r}
T=\left(\frac{\tau_{c, \max } L_{e e}}{2}+\frac{\tau_{s, \max } L_{d}}{2}\right) b_{f}, \\
\tau_{c, \max }+\tau_{\mathrm{s}, \max }=\tau_{\max },
\end{array}
$$

where $\tau_{c, \text { max }}$ and $\tau_{\mathrm{s}, \max }$ are the maximum interface bonding stress caused by flexural crack and shear force, respectively.

A coefficient $\alpha$ is introduced to represent the relationship among $\tau_{c, \max }, \tau_{s, \max }$, and $\tau_{\max }$, and their relationship is as follows:

$$
\begin{aligned}
\tau_{s, \max } & =a \tau_{\max }, \\
\tau_{c, \max } & =(1-a) \tau_{\max } .
\end{aligned}
$$

Then, the strain of the CFRP plate when the IC debonding occurs can be obtained, and the formula is as follows:

$$
\varepsilon_{f, \text { debond }}=\frac{T}{E_{f} t_{f} b_{f}}=\frac{(1-a) \tau_{\max } L_{e e}+a \tau_{\max } L_{d}}{2 E_{f} t_{f}} .
$$

It can be seen from equation (11) that only the coefficient $\alpha$ is unknown. Using the test data of 45 test beams obtained by Lu et al. [18], combined with the FEA results in this paper and the test results measured in the test of the specimens in Group A, the regression analysis was used to solve the value of $\alpha$. The regression analysis results of the relationship of $\alpha$ and $L_{e e} / L_{d}$ are shown in Figure 17. It can be learnt from the figure that $\alpha$ and $L_{e e} / L_{d}$ has a linear relationship, which can be expressed as

$$
a=3.533 \frac{L_{e e}}{L_{d}} .
$$

Substituting equations (7) and (12) into equation (11), the following equation can be obtained:

$$
\varepsilon_{f, \text { debond }}=\left(\frac{0.4148}{\sqrt{E_{f} t_{f}}}-\frac{0.0592}{L_{d}}\right) \tau_{\max } .
$$

The debonding strain values of the specimens studied by $\mathrm{Lu}$ et al. [18] were calculated by using equation (13). The calculated values from $\mathrm{Lu}$ et al. [18] and the specimens from 


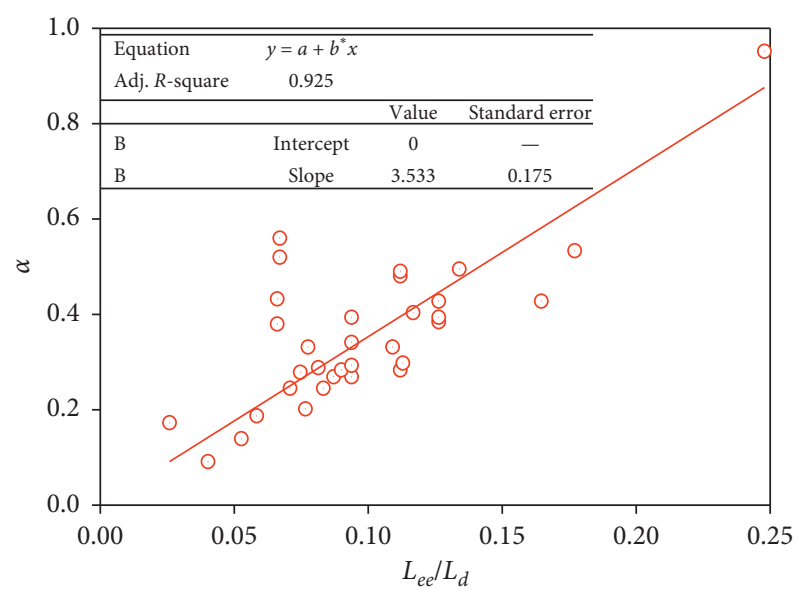

FIGURE 17: Regression analysis results of the relationship of $\alpha$ and $L_{e e} / L_{d}$.

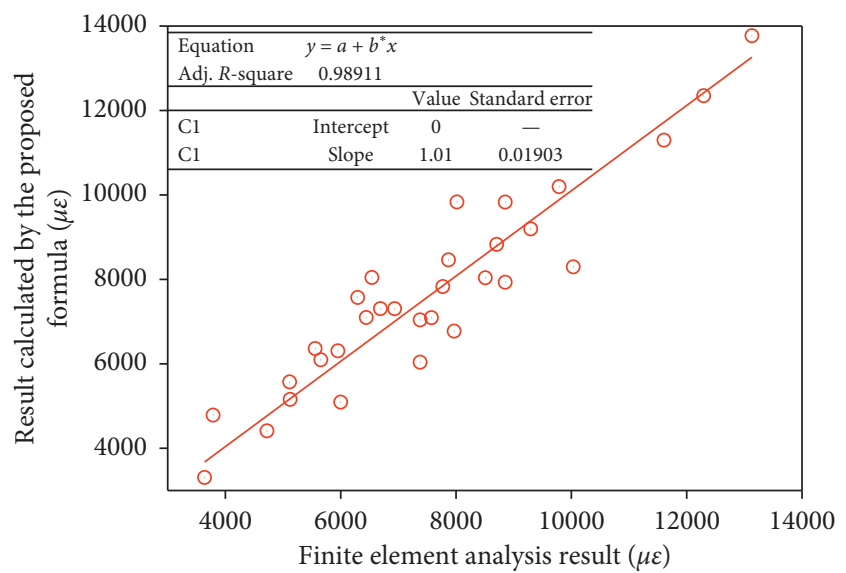

FIgURE 18: Comparison of CFRP strain values of the proposed formula with test results.

this paper are compared with the FEA results of that. The comparison result is shown in Figure 18. It can be seen from Figure 18 that there is a linear relationship between the FEA result and the calculated value of the calculation formula and the proportional coefficient is close to 1 . This indicated that the proposed formula proposed in this paper has good agreement with the FEA result and the test results. It can be used to predict the debonding strain value of the CFRP platereinforced concrete beam after high-temperature action of asphalt paving construction.

\section{Conclusions}

In this paper, based on the project of CFRP plate-reinforced box girder roof, the mechanical properties of CFRP-reinforced concrete test beams with asphalt layer were tested. The CFRP plate-concrete beams were simulated and compared with the test result, and the calculation model and formula of the debonding bearing capacity were proposed based on the numerical simulation. The main conclusions are drawn as follows:
(1) The load-deflection relationship can be greatly improved by the reinforcement of CFRP plates. It can be concluded from the experimental and numerical results that the strain distribution curves of CFRPconcrete interface can be divided into four types.

(2) Based on the introduction of the interface bond-slip relationship and double debonding failure criterion, the finite element model was established by considering the high-temperature effect of asphalt paving construction. The finite element model recommended in this study can accurately predict the crack propagation of the specimen and the strain distribution of interface by comparing the finite element results with the experimental results.

(3) The debonding failure of the CFRP plate-concrete interface element and the crack propagation can be accurately simulated in this model. The nonlinear behavior of CFRP plate-concrete interface can be better described with applying the CFRP plate-concrete interface element recommended in this paper.

(4) Considering the coupling effect of load and asphalt paving high temperature, the interface bonding stress distribution model and the calculation formula of the debonding bearing capacity were introduced to the calculation model in this study. Comparing the test results with the calculated results, it can be concluded that the debonding bearing capacity and debonding strain value of the CFRP-reinforced beam after hightemperature action can be better predicted.

\section{Data Availability}

The data used to support the findings of this study are included within the article.

\section{Conflicts of Interest}

The authors declare that there are no conflicts of interest regarding the publication of this paper.

\section{Acknowledgments}

This work was financially supported by the Brand Professional Funding Project of Jiangsu Province (Grant no. PPZY2015B143), the National Natural Science Foundation of China (Grant no. 51508368), the Postgraduate Research \& Practice Innovation Program of Jiangsu Province (Grant no. SJCX18_0879), and the Key Project of Innovation and Entrepreneurship of College Students in Jiangsu Province (Grant no. 201810332019Z).

\section{References}

[1] J. Tian, X. W. Wu, Y. Zheng, Y. F. Du, and X. K. Quan, "Experimental study and mixed-dimensional FE analysis of T-rib GFRP plate-concrete composite bridge decks," Advances in Materials Science and Engineering, vol. 2018, Article ID 7531912, 13 pages, 2018. 
[2] Z. Draidi, T. T. Bui, A. Limam, H. V. Tran, and A. Bennani, "Buckling behavior of metallic cylindrical shell structures strengthened with CFRP composite," Advances in Civil Engineering, vol. 2018, Article ID 4231631, 13 pages, 2018.

[3] Z. Y. Sun, Y. Yang, W. L. Yan, G. Wu, and X. Y. He, "Momentcurvature behaviors of concrete beams singly reinforced by steel-FRP composite bars," Advances in Civil Engineering, vol. 2017, Article ID 1309629, 14 pages, 2017.

[4] J. F. Choo, Y.-C. Choi, S.-J. Kwon, K.-T. Park, and S.-W. Yoo, "Low-cycle flexural fatigue behavior of concrete beam reinforced with hybrid FRP-steel rebar," Advances in Civil Engineering, vol. 2018, Article ID 6986047, 13 pages, 2018.

[5] B. Kromoser, P. Preinstorfer, and J. Kollegger, "Building lightweight structures with carbon-fiber-reinforced polymer-reinforced ultra-high-performance concrete: research approach, construction materials, and conceptual design of three building components: research approach, construction materials, and conceptual design of three building components," Structural Concrete, vol. 20, no. 2, pp. 730-744, 2019.

[6] J. Shi, H. Zhu, Z. Wu, R. Seracino, and G. Wu, "Bond behavior between basalt fiber-reinforced polymer sheet and concrete substrate under the coupled effects of freeze-thaw cycling and sustained load," Journal of Composites for Construction, vol. 17, no. 4, pp. 530-542, 2013.

[7] D. Y. Li, P. Y. Huang, G. Qin, X. H. Zheng, and X. Y. Guo, "Fatigue crack propagation behavior of RC beams strengthened with CFRP under high temperature and high humidity environment," International Journal of Polymer Science, vol. 2017, Article ID 1247949, 11 pages, 2017.

[8] X. Wang and M. Petrů, "Mode I fracture evaluation of CFRPto-concrete interfaces subject to aggressive environments agents: freeze-thaw cycles, acid and alkaline solution," Composites Part B: Engineering, vol. 168, pp. 581-588, 2019.

[9] J. M. Gallego, J. Michels, and C. Czaderski, "Influence of the asphalt pavement on the short-term static strength and longterm behaviour of RC slabs strengthened with externally bonded CFRP strips," Engineering Structures, vol. 150, pp. 481-496, 2017.

[10] Y. Tao and J. F. Chen, "Concrete damage plasticity model for modeling FRP-to-concrete bond behavior," Journal of Composites for Construction, vol. 19, no. 1, Article ID 04014026, 2015.

[11] R. A. Daud, L. S. Cunningham, and Y. C. Wang, "New model for post-fatigue behaviour of CFRP to concrete bond interface in single shear," Composite Structures, vol. 163, pp. 63-76, 2017.

[12] A. M. H. Kadhim, H. A. Numan, and M. Özakça, "Flexural strengthening and rehabilitation of reinforced concrete beam using BFRP composites: finite element approach," Advances in Civil Engineering, vol. 2019, Article ID 4981750, 17 pages, 2019.

[13] X. Z. Lu, L. P. Ye, J. G. Teng, and J. J. Jiang, "Meso-scale finite element model for FRP sheets/plates bonded to concrete," Engineering Structures, vol. 27, no. 4, pp. 564-575, 2005.

[14] J. G. Teng, S. S. Zhang, J. G. Dai, and J. F. Chen, "Threedimensional meso-scale finite element modeling of bonded joints between a near-surface mounted FRP strip and concrete," Computers \& Structures, vol. 117, no. 2, pp. 105-117, 2013.

[15] M. Coelho, A. Caggiano, J. Sena-Cruz, and L. Neves, "Fracture-based interface model for NSM FRP systems in concrete," Composite Structures, vol. 152, pp. 816-828, 2016.
[16] A. Abbasloo and M. R. Maheri, "Prediction of modal damping of FRP-honeycomb sandwich panels with arbitrary geometries," Latin American Journal of Solids and Structures, vol. 14, no. 1, pp. 17-35, 2017.

[17] X. Z. Lu, T. Zhuang, L. P. Ye, and J. J. Jiang, "Finite element analysis of debonding at the interface between FRP sheet and concrete," Engineering Mechanics, vol. 21, no. 6, pp. 45-50, 2004.

[18] X. Z. Lu, L. P. Ye, J. G. Teng et al., "Bond-slip model for FRPto-concrete interface," Journal of Building Structures, vol. 26, no. 4, pp. 10-18, 2005.

[19] O. Buyukozturk, "Nonlinear analysis of reinforced concrete structures," Computers \& Structures, vol. 7, no. 1, pp. 149-156, 1977.

[20] H. Yuan, J. G. Teng, R. Seracino, Z. S. Wu, and J. Yao, "Fullrange behavior of FRP-to-concrete bonded joints," Engineering Structures, vol. 26, no. 5, pp. 553-565, 2004.

[21] F. Bencardino, G. Spadea, and R. N. Swamy, "Strength and ductility of reinforced concrete beams externally reinforced with carbon fiber fabric," ACI Structural Journal, vol. 99, no. 2, pp. 163-171, 2002.

[22] X. Yuan, C. Y. Zhu, J. B. Hu, and Y. Y. Zhang, "Crack and mechanical behavior of CFRP plate-reinforced bridge roofs under high temperature with different anchoring measures," Latin American Journal of Solids and Structures, vol. 16, no. 6, pp. 1-20, 2019. 


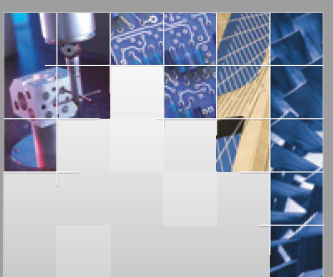

\section{Enfincering}
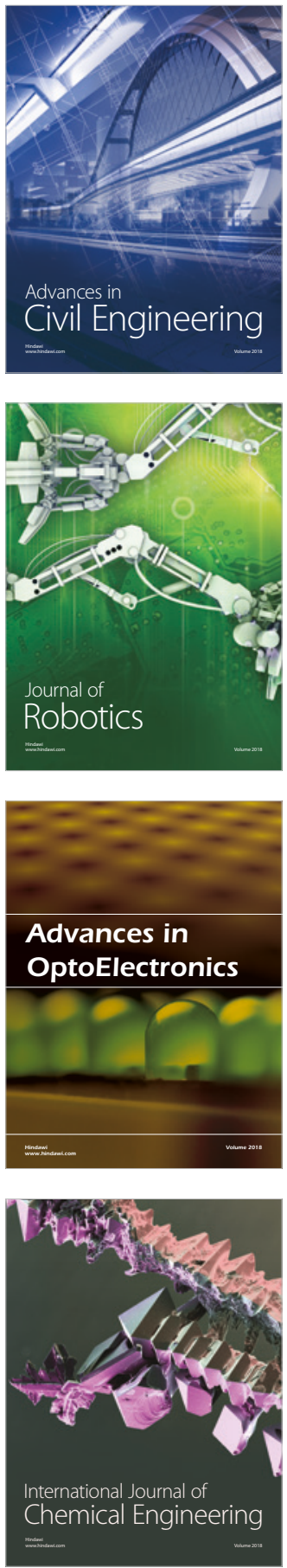

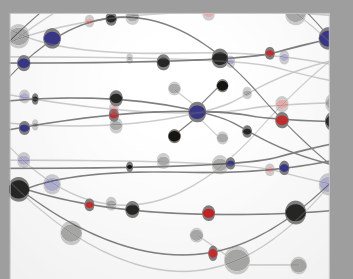

\section{Rotating \\ Machinery}

The Scientific World Journal

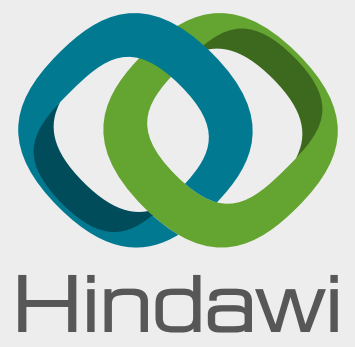

Submit your manuscripts at

www.hindawi.com
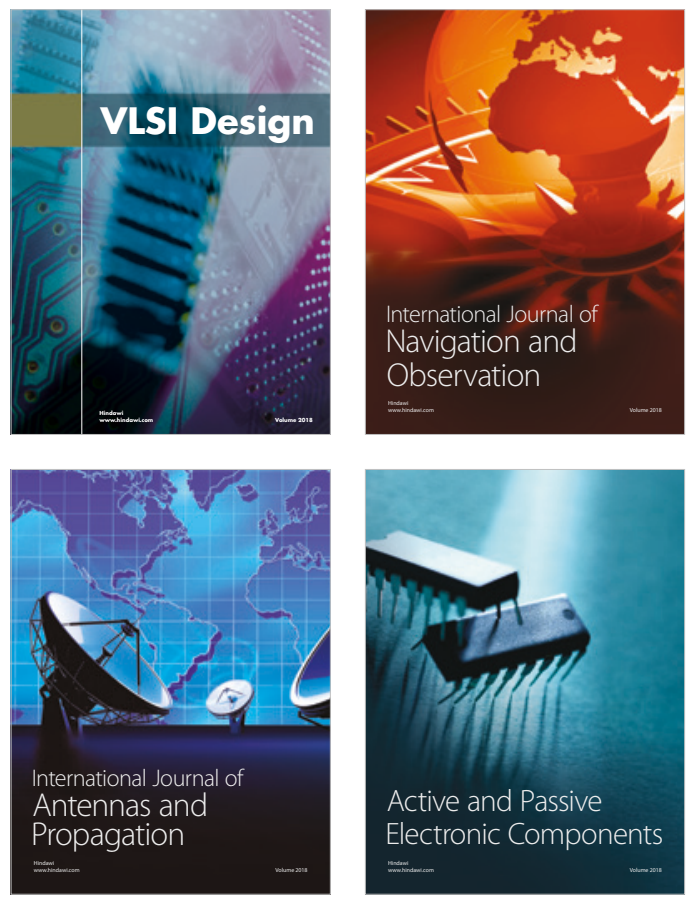
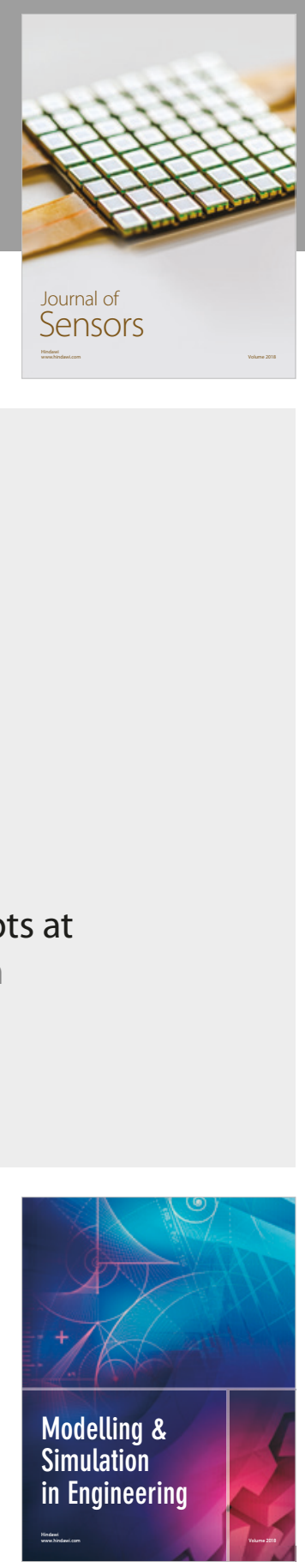

\section{Advances \\ Multimedia}
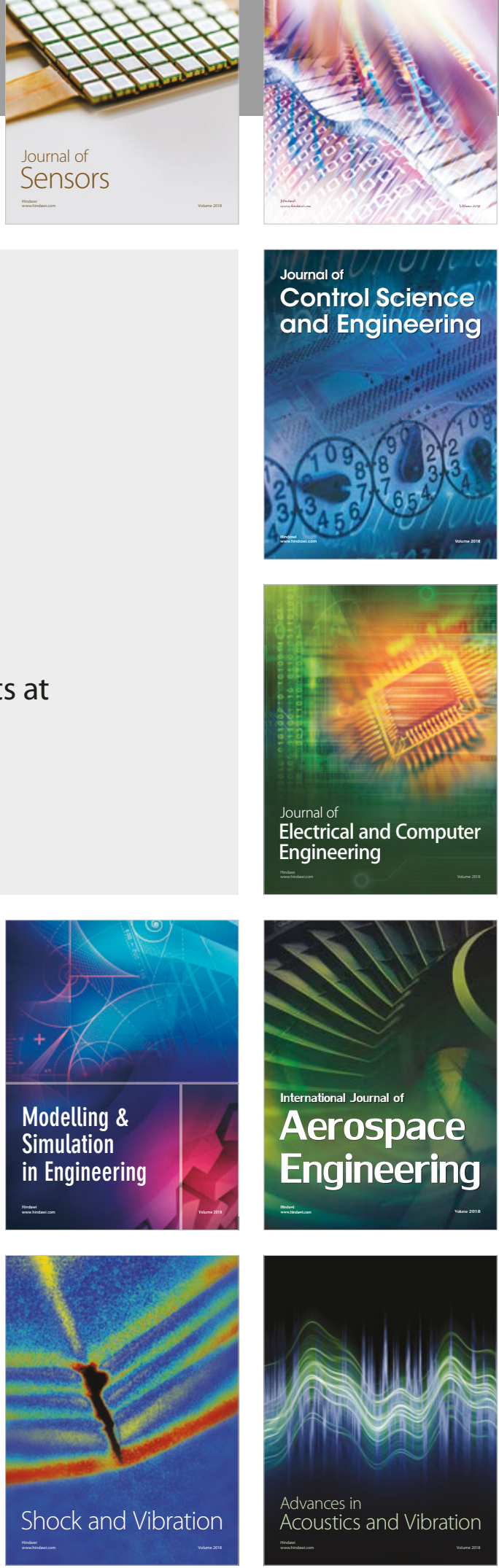